Review Article

\title{
Adherence to Artemisinin-Based Combination Therapy for the Treatment of Uncomplicated Malaria: A Systematic Review and Meta-Analysis
}

\author{
Ahmad M. Yakasai, ${ }^{1}$ Muhammad Hamza, ${ }^{2}$ Mahmood M. Dalhat, ${ }^{2}$ \\ Musa Bello, ${ }^{3}$ Muktar A. Gadanya, ${ }^{3}$ Zuwaira M. Yaqub, \\ Daiyabu A. Ibrahim, ${ }^{5}$ and Fatimah Hassan-Hanga ${ }^{6}$ \\ ${ }^{1}$ Infectious and Tropical Diseases Unit, Public Health and Diagnostic Institute, College of Medical Sciences, Northwest University, \\ PMB 3220, Kano, Nigeria \\ ${ }^{2}$ Infectious and Tropical Diseases Unit, Department of Medicine, Aminu Kano Teaching Hospital, Bayero University, \\ PMB 3452, Kano, Nigeria \\ ${ }^{3}$ Department of Community Medicine, Aminu Kano Teaching Hospital, Bayero University, PMB 3452, Kano, Nigeria \\ ${ }^{4}$ Department of Pharmacy, Aminu Kano Teaching Hospital, PMB 3452, Kano, Nigeria \\ ${ }^{5}$ Department of Medicine, Aminu Kano Teaching Hospital, Bayero University, PMB 3452, Kano, Nigeria \\ ${ }^{6}$ Infectious and Tropical Diseases Unit, Department of Paediatrics, Aminu Kano Teaching Hospital, Bayero University, \\ PMB 3452, Kano, Nigeria
}

Correspondence should be addressed to Ahmad M. Yakasai; ahmadmaifada@gmail.com

Received 16 December 2014; Revised 3 May 2015; Accepted 4 May 2015

Academic Editor: Aditya Prasad Dash

Copyright (C) 2015 Ahmad M. Yakasai et al. This is an open access article distributed under the Creative Commons Attribution License, which permits unrestricted use, distribution, and reproduction in any medium, provided the original work is properly cited.

Adherence to artemisinin-based combination therapy (ACT) is not clearly defined. This meta-analysis determines the prevalence and predictors of adherence to ACT. Twenty-five studies and six substudies met the inclusion criteria. The prevalence of ACT adherence in the public sector was significantly higher compared to retail sector ( $76 \%$ and $45 \%$, resp., $P<0.0001)$. However, ACT adherence was similar across different ACT dosing regimens and formulations. In metaregression analysis prevalence estimates of adherence significantly decrease with increasing year of study publication $(P=0.046)$. Factors found to be significant predictors of ACT adherence were years of education $\geq 7$ \{odds ratio $(\mathrm{OR})(95 \% \mathrm{CI})=1.63(1.05-2.53)\}$, higher income $\{2.0(1.35-2.98)\}$, fatty food $\{4.6(2.49-8.50)\}$, exact number of pills dispensed $\{4.09(1.60-10.7)\}$, and belief in traditional medication for malaria $\{0.09$ (0.01-0.78)\}. The accuracy of pooled estimates could be limited by publication bias, and differing methods and thresholds of assessing adherence. To improve ACT adherence, educational programs to increase awareness and understanding of ACT dosing regimen are interventions urgently needed. Patients and caregivers should be provided with an adequate explanation at the time of prescribing and/or dispensing ACT.

\section{Introduction}

Malaria is endemic in several countries in Africa, Asia, and South America. It is associated with high morbidity and mortality especially in children under five years of age. The economic loss due to malaria infection is huge in malaria endemic regions. It has been estimated that, in some countries of Sub-Saharan Africa (SSA), up to $10 \%$ of monthly income could be spent on procuring a complete dose of ACT for a child $[1,2]$. The epidemic of malaria has been fuelled by widespread resistance to cheap antimalarial drugs like chloroquine. Thus, there was an urgent need to shift from monotherapy to combination therapy in order to prevent further development of resistance [3]. In 2001, the World Health Organization (WHO) recommended artemisinin-based combination therapy (ACT) as the first line therapy for 
uncomplicated malaria [3]. Since then adoption of ACT in malaria endemic countries especially in SSA has been slow due to the lack of understanding of the concept of ACT, its fundamental principles, and its high cost. Other problems relate to the nonavailability of appropriate paediatric formulations and the erratic supply of ACTs in endemic areas. Adoption of ACT as the first line treatment for uncomplicated malaria could have positive impact on individuals, their families, and the community at large by reducing incidence of complications, preventing development of multidrug resistant malaria species and reducing the socioeconomic burden of malaria infection. In addition ACT reduces morbidity and mortality from malaria indirectly by preventing progression of uncomplicated malaria to severe malaria. ACTs not only are good in treatment of malaria but also serve as tools for prevention and control of malaria due to their ability to reduce the infectivity of mosquitoes especially in areas of low or moderate malaria transmission [4].

Several ACT combinations available include artemetherlumefantrine (AL), artesunate-amodiaquine (AS/AQ), artesunate-mefloquine (AS/MQ), artesunate-chlorproguanil-dapsone (AS/CD), artesunate-sulphadoxine-pyrimethamine (AS/ $\mathrm{SP})$, dihydroartemisinin-piperaquine (DA/PQ), artesunatepiperazine (AS/PZ), and artesunate-atovaquone-proguanil (A/AP) [5]. Out of these ACT combinations WHO recommended AL, AS/MQ, AS/AQ, and AS/SP [6]. Several countries have now adopted ACTs as the first line agents for uncomplicated malaria [7]. However, a major challenge with ACT is that because of the rapid response and resolution of symptoms patients or caregivers of children tend to terminate treatment prematurely keeping the remaining tablets for future malaria episodes $[8,9]$. Studies conducted across the world have reported varying levels of adherence to ACT both in the public and retail sectors. Moreover, two recently published reviews also noted this wide variation in adherence to ACT $[10,11]$. This meta-analysis was therefore conducted to derive pooled estimates of prevalence and predictors of adherence to ACTs since adherence has been shown to be a key challenge in the implementation and adoption of ACT [12].

\section{Materials and Methods}

2.1. Process of Article Search and Selection Criteria. Peerreviewed articles published in English language were searched for electronically in Google Scholar, MEDLINE, EMBASE, AJOL, Web of Science, Cochrane database, and other relevant web sites. Infectious diseases journals, malaria journals, and public health journals were also searched. Medical Subject Heading (MeSH) terms applied in different combinations include "Malaria," "adherence," "non adherence," "predictors," "risk factors," "artemisinin," "antimalarial," and "treatment." Search was conducted up to April 25th, 2015. All studies that satisfied the following criteria were included.

(1) Reported prevalence and/or predictors of adherence to ACT given for the treatment of uncomplicated malaria.

(2) Reported method of assessing adherence.
Two reviewers independently extracted information from the articles. Disagreements were resolved by mutual consensus and/or consultation of third reviewer.

2.2. Assessment of Study Quality. The Downs and Black checklist was used to assess methodological quality of included studies [13]. This meta-analysis was conducted and reported according to the guidelines of "Preferred Reporting Items for Systematic Reviews and Meta-Analysis" (PRISMA) and "Meta-Analysis of Observational Studies in Epidemiology" (MOOSE) [14, 15].

2.3. Data Analysis. For each of the included studies we recorded the prevalence of adherence to ACT and the 95\% Confidence Interval (CI), the standard error, the log of the prevalence, the odds ratio of adherence, and the log of odds ratio. DerSimonian and Laird meta-analyses were performed on the prevalence and odds ratio of adherence to ACT [16]. The level of statistical heterogeneity was used to select an appropriate model for the meta-analysis. Specifically, where we encountered significant heterogeneity $\left(I^{2}\right.$ statistics $>50 \%$ ), a random effects model (REM) is applied whereas if heterogeneity is not significant we apply a fixed effects model (FEM). Publication bias was assessed with Begg's and Egger's tests $[17,18]$. Because these tests could be inconsistent and sometimes a funnel plot could be misleading, we considered publication bias to be present if both tests were able to detect it $[19,20]$. Sensitivity analysis was done to examine if any of the studies exerts profound influence on meta-analysis estimates [21]. Quality assessment of included studies was also done. Stata version 12 (Stata Corp., College Station, TX, USA) was used for data analysis.

2.4. Characteristics of Studies Included in the Meta-Analysis. As shown in Figure 1, thirty-one studies (twenty-five main studies and six substudies) [12, 22-45] met the inclusion criteria and their characteristics are shown in Table 1. Twentytwo of the studies (and three substudies) were done in the public sector where medications were given for free and dispensed by health professionals with clear instructions [22$35,37,39-45]$. The other six studies were done in the retail sector where patients or caregivers buy medications from drug stores or supermarkets without proper instructions on how to take them $[12,36,38,40]$. All the studies included in the systematic review and meta-analysis had satisfactory data quality as shown in Table 2 . Study subjects were mainly children, adolescents, and adults. Questions on adherence to ACT were responded to by adults, adolescents, and caregivers of children.

\section{Results}

3.1. Public Sector versus Retail Sector. As indicated in Figure 2, using REM the pooled prevalence (95\% CI) of adherence to ACT from the twenty-five studies done in the public sector was $75.78 \%(68.08 \%-83.49 \%)$. Significant statistical heterogeneity was present $\left(I^{2}=95.3 \%, P<0.0001\right)$. There was publication bias indicated by significant $P$ values in both Begg's and Egger's tests (0.002 and 0.012, resp.). Sensitivity 
TABLE 1: Characteristics of studies included in the systematic review and meta-analysis.

\begin{tabular}{|c|c|c|c|c|c|c|}
\hline Author/year & Country & Sample size & Endemicity & ACT & Adherence measure & Comments/sources of bias \\
\hline $\begin{array}{l}\text { Ajayi et al. } 2008 \\
{[22]}\end{array}$ & Nigeria & 288 & High & $\mathrm{AL}$ & $\begin{array}{l}\text { Blister pack/caregivers } \\
\text { recall }\end{array}$ & $\begin{array}{l}>97 \% \text { of CMDs prescribing } \\
\text { correct ACT doses }\end{array}$ \\
\hline $\begin{array}{l}\text { Ajayi et al. } 2008 \\
\text { [22] }\end{array}$ & Ghana & 382 & High & $\mathrm{AS} / \mathrm{AQ}$ & $\begin{array}{l}\text { Blister pack/caregivers } \\
\text { recall }\end{array}$ & $\begin{array}{l}>97 \% \text { of CMDs prescribing } \\
\text { correct ACT doses }\end{array}$ \\
\hline $\begin{array}{l}\text { Ajayi et al. } 2008 \\
{[22]}\end{array}$ & Uganda & 619 & High & $\mathrm{AL}$ & $\begin{array}{l}\text { Blister pack/caregivers } \\
\text { recall }\end{array}$ & $\begin{array}{l}>97 \% \text { of CMDs prescribing } \\
\text { correct ACT doses }\end{array}$ \\
\hline $\begin{array}{l}\text { Asante et al. } 2009 \\
{[23]}\end{array}$ & Ghana & 401 & High & $\mathrm{AS} / \mathrm{AQ}$ & Blister pack & $\begin{array}{l}\text { Home visit to supervise } \\
\text { treatment which could influence } \\
\text { adherence }\end{array}$ \\
\hline $\begin{array}{l}\text { Bell et al. } 2009 \\
{[28]}\end{array}$ & Malawi & 209 & High & $\mathrm{AL}$ & $\begin{array}{l}\text { Questionnaire and } \\
\text { electronic device }\end{array}$ & Blood LU assayed on day 7 \\
\hline $\begin{array}{l}\text { Chinbuah et al. } \\
2006[34]\end{array}$ & Ghana & NA & High & $\mathrm{AL}$ & Blister pack & $\begin{array}{l}\text { Majority of children receiving } \\
\text { correct dose of } \mathrm{AL}\end{array}$ \\
\hline $\begin{array}{l}\text { Fogg et al. } 2004 \\
{[31]}\end{array}$ & Uganda & 210 & High & $\mathrm{AL}$ & Blister pack & $\begin{array}{l}\text { Educated semiurban population } \\
\text { blood lumefantrine level assayed }\end{array}$ \\
\hline $\begin{array}{l}\text { Kabanywanyi et } \\
\text { al. } 2010[25]\end{array}$ & Tanzania & 522 & NR & $\mathrm{AL}$ & Blister pack & $\begin{array}{l}\text { Pictorial instruction available, } \\
\text { questionnaire not validated }\end{array}$ \\
\hline $\begin{array}{l}\text { Kachur et al. } 2004 \\
{[32]}\end{array}$ & Tanzania & 253 & Moderate & AS/SP & Blister pack/self-report & Socioeconomic status assessed \\
\hline $\begin{array}{l}\text { Lawford et al. } \\
2011[24]\end{array}$ & Kenya & 918 & Low/moderate & $\mathrm{AL}$ & Blister pack/self-report & $\begin{array}{l}\text { Validity of translated } \\
\text { questionnaire not mentioned }\end{array}$ \\
\hline $\begin{array}{l}\text { Mace et al. } 2011 \\
{[30]}\end{array}$ & Malawi & 868 & High & $\mathrm{AL}$ & Pill count/dose recall & Pictorial instructions provided \\
\hline $\begin{array}{l}\text { Beer et al. } 2009 \\
\text { [27] }\end{array}$ & Tanzania & 195 & Moderate & AS/AQ & Pill count/self-report & $\begin{array}{l}>50 \% \text { of nonadherence was due } \\
\text { to misunderstanding of } \\
\text { instructions }\end{array}$ \\
\hline $\begin{array}{l}\text { Simba et al. } 2012 \\
\text { [35] }\end{array}$ & Tanzania & 444 & High & $\mathrm{AL}$ & Self-report & $\begin{array}{l}\text { Plasma LU concentration } \\
\text { assayed, pictorial instruction } \\
\text { provided, and questionnaire } \\
\text { validated }\end{array}$ \\
\hline $\begin{array}{l}\text { Depoortere et al. } \\
2004[33]\end{array}$ & Zambia & 142 & Moderate & AS/SP & Blister pack & No adequate dosage instructions \\
\hline $\begin{array}{l}\text { Gerstl et al. } 2010 \\
{[26]}\end{array}$ & Sierra Leone & 118 & High & $\mathrm{AS} / \mathrm{AQ}$ & Blister pack & $\begin{array}{l}37 \% \text { given wrong dosage } \\
\text { instructions }\end{array}$ \\
\hline $\begin{array}{l}\text { Lemma et al. } 2011 \\
\text { [29] }\end{array}$ & Ethiopia & 155 & Low & $\mathrm{AL}$ & Blister pack/self-report & $\begin{array}{l}\text { Study done at peak of malaria } \\
\text { transmission }\end{array}$ \\
\hline $\begin{array}{l}\text { Onyango et al. } \\
2012[12] \\
\end{array}$ & Kenya & 297 & Low & $\mathrm{AL}$ & Pill count/self-report & $\begin{array}{l}\text { Covered long distance to get } \\
\text { ACT, questionnaire validated }\end{array}$ \\
\hline $\begin{array}{l}\text { Cohen et al. } 2012 \\
{[36]}\end{array}$ & Uganda & 152 & Low & $\mathrm{AL}$ & Blister pack/self-report & $\begin{array}{l}\text { Drug shops licensed, ACT } \\
\text { heavily subsidized, and shop } \\
\text { attendants trained and } \\
\text { supervised }\end{array}$ \\
\hline $\begin{array}{l}\text { Achan et al. } 2009 \\
{[37]}\end{array}$ & Uganda & 175 & Low & $\mathrm{AL}$ & Blister pack & Adequate instruction given \\
\hline $\begin{array}{l}\text { Amponsah et al. } \\
2015 \text { [38] }\end{array}$ & Ghana & 219 & High & $\mathrm{AL}$ & Pill count & Questionnaire validated \\
\hline $\begin{array}{l}\text { Amponsah et al. } \\
2015[38]\end{array}$ & Ghana & 55 & High & $\mathrm{AS} / \mathrm{AQ}$ & Pill count & Questionnaire validated \\
\hline $\begin{array}{l}\text { Amponsah et al. } \\
2015[38]\end{array}$ & Ghana & 26 & High & $\mathrm{AS} / \mathrm{PP}$ & Pill count & Questionnaire validated \\
\hline $\begin{array}{l}\text { Aung et al. } 2015 \\
{[39]}\end{array}$ & Myanmar & 161 & High & $\mathrm{AL}$ & Pill count/self-report & Good dosage instructions given \\
\hline
\end{tabular}


TABLE 1: Continued.

\begin{tabular}{|c|c|c|c|c|c|c|}
\hline Author/year & Country & Sample size & Endemicity & $\mathrm{ACT}$ & Adherence measure & Comments/sources of bias \\
\hline $\begin{array}{l}\text { Bruxvoort et al. } \\
2015[40]\end{array}$ & Tanzania & 572 & Low & $\mathrm{AL}$ & Pill count/self-report & $\begin{array}{l}\text { Taking first dose at health facility } \\
\text { associated with good adherence }\end{array}$ \\
\hline $\begin{array}{l}\text { Bruxvoort et al. } \\
2015 \text { [40] }\end{array}$ & Tanzania & 450 & Low & $\mathrm{AL}$ & Pill count/self-report & $\begin{array}{l}\text { Several drug shops not yet } \\
\text { accredited and not receiving } \\
\text { training }\end{array}$ \\
\hline $\begin{array}{l}\text { Congpuong et al. } \\
2010[41]\end{array}$ & Thailand & 240 & High & AS/MQ & $\begin{array}{l}\text { Day } 3 \text { whole blood MQ } \\
\text { concentration and } \\
\text { self-report }\end{array}$ & $\begin{array}{l}\text { Self-report failing to identify } \\
2.4 \% \text { of subjects with poor } \\
\text { adherence }\end{array}$ \\
\hline $\begin{array}{l}\text { Ewing et al. } 2015 \\
{[42]}\end{array}$ & Malawi & 101 & High & $\mathrm{AL}$ & $\begin{array}{l}\text { Pill count, blister pack, } \\
\text { and self-report }\end{array}$ & $\begin{array}{l}\text { Underdosing due to loss of } \\
\text { medication, children followed up } \\
\text { for } 3 \text { years to monitor long term } \\
\text { effects of ACT }\end{array}$ \\
\hline $\begin{array}{l}\text { Ewing et al. } 2015 \\
\text { [42] }\end{array}$ & Malawi & 117 & High & $\mathrm{DA} / \mathrm{PQ}$ & $\begin{array}{l}\text { Pill count, blister pack, } \\
\text { and self-report }\end{array}$ & $\begin{array}{l}\text { Underdosing due to loss of } \\
\text { medication, children followed up } \\
\text { for } 3 \text { years to monitor long term } \\
\text { effects of ACT }\end{array}$ \\
\hline $\begin{array}{l}\text { Gore-Langton et } \\
\text { al. } 2015 \text { [43] }\end{array}$ & Kenya & 195 & Low & $\mathrm{AL}$ & $\begin{array}{l}\text { Self-report and blister } \\
\text { pack }\end{array}$ & $\begin{array}{l}\text { Study area affected by conflict } \\
\text { leading to poor health delivery } \\
\text { services }\end{array}$ \\
\hline $\begin{array}{l}\text { Siddiqui et al. } \\
2015 \text { [44] }\end{array}$ & DR Congo & 108 & High & AS/AQ & $\begin{array}{l}\text { Self-report and blister } \\
\text { pack }\end{array}$ & $\begin{array}{l}\text { Poor understanding of the need } \\
\text { to complete treatment schedule }\end{array}$ \\
\hline $\begin{array}{l}\text { Ogolla et al. } 2013 \\
\text { [45] }\end{array}$ & Kenya & 62 & Low & $\mathrm{AL}$ & $\begin{array}{l}\text { Pill count, blister pack, } \\
\text { and self-report }\end{array}$ & $\begin{array}{l}\text { Malaria was microscopically } \\
\text { confirmed. The sixth ACT dose } \\
\text { was the most commonly } \\
\text { forgotten tablet }\end{array}$ \\
\hline
\end{tabular}

ACT: artemisinin-based combination therapy, AL: artemether-lumefantrine, AQ: amodiaquine, AS: artesunate, CMDs: community medicine distributors, DA: dihydroartemisinin, PQ: piperaquine, PP: piperazine, and SP: sulphadoxine-pyrimethamine.

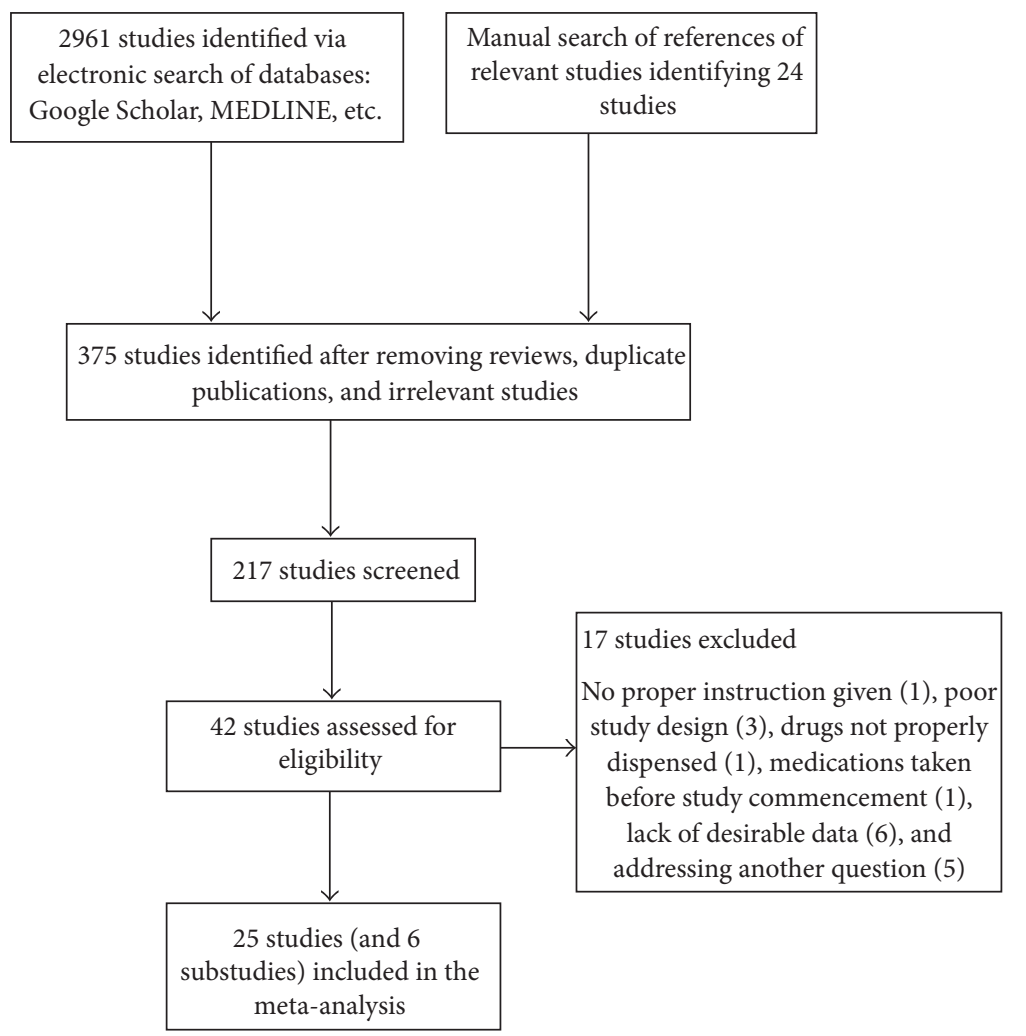

FIGURE 1: Flow diagram for selecting studies for review and meta-analysis. 
TABLE 2: Quality assessment of included studies.

\begin{tabular}{|c|c|c|c|c|c|c|c|}
\hline Author & $\begin{array}{c}\text { Adequate } \\
\text { sample size }\end{array}$ & $\begin{array}{c}\text { Reported } \\
\text { baseline } \\
\text { characteristics }\end{array}$ & Randomization & $\begin{array}{l}\text { Unannounced } \\
\text { home visit }\end{array}$ & $\begin{array}{c}\text { Reported } \\
\text { adherence } \\
\text { measure }\end{array}$ & $\begin{array}{l}\text { Addressed lost } \\
\text { to follow-up }\end{array}$ & $\begin{array}{c}\text { Excluded } \\
\text { confounders }\end{array}$ \\
\hline $\begin{array}{l}\text { Ajayi et al. } 2008 \\
\text { [22] }\end{array}$ & $\mathrm{Y}$ & $\mathrm{Y}$ & $\mathrm{N}$ & $\mathrm{NC}$ & $\mathrm{Y}$ & $\mathrm{NC}$ & $\mathrm{Y}$ \\
\hline $\begin{array}{l}\text { Asante et al. } \\
2009 \text { [23] }\end{array}$ & $\mathrm{Y}$ & $\mathrm{Y}$ & $\mathrm{Y}$ & $\mathrm{NC}$ & $\mathrm{Y}$ & $\mathrm{Y}$ & $\mathrm{Y}$ \\
\hline $\begin{array}{l}\text { Bell et al. } 2009 \\
{[28]}\end{array}$ & $\mathrm{Y}$ & $\mathrm{Y}$ & $\mathrm{Y}$ & $\mathrm{N}$ & $\mathrm{Y}$ & $\mathrm{N}$ & $\mathrm{Y}$ \\
\hline $\begin{array}{l}\text { Chinbuah et al. } \\
2006[34]\end{array}$ & NA & $\mathrm{Y}$ & $\mathrm{N}$ & $\mathrm{N}$ & $\mathrm{Y}$ & NR & $\mathrm{N}$ \\
\hline $\begin{array}{l}\text { Fogg et al. } 2004 \\
{[31]}\end{array}$ & $\mathrm{Y}$ & $\mathrm{Y}$ & $\mathrm{N}$ & $\mathrm{Y}$ & $\mathrm{Y}$ & NR & $\mathrm{Y}$ \\
\hline $\begin{array}{l}\text { Kabanywanyi et } \\
\text { al. } 2010 \text { [25] }\end{array}$ & $\mathrm{Y}$ & $\mathrm{Y}$ & $\mathrm{Y}$ & $\mathrm{N}$ & $\mathrm{Y}$ & NR & $\mathrm{N}$ \\
\hline $\begin{array}{l}\text { Kachur et al. } \\
2004 \text { [32] }\end{array}$ & $\mathrm{Y}$ & $\mathrm{Y}$ & $\mathrm{Y}$ & $\mathrm{Y}$ & $\mathrm{Y}$ & NR & $\mathrm{Y}$ \\
\hline $\begin{array}{l}\text { Lawford et al. } \\
2011[24]\end{array}$ & $\mathrm{Y}$ & $\mathrm{Y}$ & $\mathrm{N}$ & $\mathrm{Y}$ & $\mathrm{Y}$ & NR & $\mathrm{Y}$ \\
\hline $\begin{array}{l}\text { Mace et al. } 2011 \\
{[30]}\end{array}$ & $\mathrm{Y}$ & $\mathrm{Y}$ & $\mathrm{N}$ & $\mathrm{Y}$ & $\mathrm{Y}$ & $\mathrm{Y}$ & $\mathrm{Y}$ \\
\hline $\begin{array}{l}\text { Beer et al. } 2009 \\
\text { [27] }\end{array}$ & $\mathrm{Y}$ & $\mathrm{Y}$ & $\mathrm{N}$ & $\mathrm{Y}$ & $\mathrm{Y}$ & $\mathrm{Y}$ & $\mathrm{Y}$ \\
\hline $\begin{array}{l}\text { Simba et al. } 2012 \\
{[35]}\end{array}$ & $\mathrm{Y}$ & $\mathrm{Y}$ & $\mathrm{N}$ & $\mathrm{Y}$ & $\mathrm{Y}$ & $\mathrm{Y}$ & $\mathrm{Y}$ \\
\hline $\begin{array}{l}\text { Depoortere et } \\
\text { al. } 2004[33] \\
\end{array}$ & $\mathrm{Y}$ & $\mathrm{Y}$ & $\mathrm{N}$ & $\mathrm{Y}$ & $\mathrm{Y}$ & $\mathrm{Y}$ & $\mathrm{Y}$ \\
\hline $\begin{array}{l}\text { Gerstl et al. } 2010 \\
{[26]}\end{array}$ & $\mathrm{Y}$ & $\mathrm{Y}$ & $\mathrm{N}$ & $\mathrm{Y}$ & $\mathrm{Y}$ & $\mathrm{Y}$ & $\mathrm{Y}$ \\
\hline $\begin{array}{l}\text { Lemma et al. } \\
2011[29]\end{array}$ & $\mathrm{Y}$ & $\mathrm{Y}$ & $\mathrm{N}$ & $\mathrm{Y}$ & $\mathrm{Y}$ & $\mathrm{Y}$ & $\mathrm{Y}$ \\
\hline $\begin{array}{l}\text { Onyango et al. } \\
2012[12]\end{array}$ & $\mathrm{Y}$ & $\mathrm{Y}$ & $\mathrm{N}$ & $\mathrm{NC}$ & $\mathrm{Y}$ & NR & $\mathrm{Y}$ \\
\hline $\begin{array}{l}\text { Cohen et al. } \\
2012[36]\end{array}$ & $\mathrm{Y}$ & $\mathrm{Y}$ & $\mathrm{Y}$ & $\mathrm{Y}$ & $\mathrm{Y}$ & $\mathrm{Y}$ & $\mathrm{Y}$ \\
\hline $\begin{array}{l}\text { Achan et al. } \\
2009 \text { [37] }\end{array}$ & $\mathrm{Y}$ & $\mathrm{Y}$ & $\mathrm{N}$ & $\mathrm{Y}$ & $\mathrm{Y}$ & $\mathrm{NC}$ & $\mathrm{Y}$ \\
\hline $\begin{array}{l}\text { Amponsah et al. } \\
2015 \text { [38] }\end{array}$ & $\mathrm{Y}$ & $\mathrm{Y}$ & $\mathrm{N}$ & $\mathrm{N}$ & $\mathrm{Y}$ & $\mathrm{Y}$ & $\mathrm{Y}$ \\
\hline $\begin{array}{l}\text { Aung et al. } 2015 \\
\text { [39] }\end{array}$ & $\mathrm{Y}$ & $\mathrm{Y}$ & $\mathrm{N}$ & $\mathrm{Y}$ & $\mathrm{Y}$ & $\mathrm{Y}$ & $\mathrm{Y}$ \\
\hline $\begin{array}{l}\text { Bruxvoort et al. } \\
2015 \text { [40] }\end{array}$ & $\mathrm{Y}$ & $\mathrm{Y}$ & $\mathrm{N}$ & $\mathrm{NC}$ & $\mathrm{Y}$ & $\mathrm{Y}$ & $\mathrm{Y}$ \\
\hline $\begin{array}{l}\text { Congpuong et } \\
\text { al. } 2010[41]\end{array}$ & $\mathrm{Y}$ & $\mathrm{Y}$ & $\mathrm{N}$ & $\mathrm{N}$ & $\mathrm{Y}$ & NR & $\mathrm{Y}$ \\
\hline $\begin{array}{l}\text { Ewing et al. } 2015 \\
{[42]}\end{array}$ & $\mathrm{Y}$ & $\mathrm{Y}$ & $\mathrm{Y}$ & $\mathrm{N}$ & $\mathrm{Y}$ & $\mathrm{Y}$ & $\mathrm{Y}$ \\
\hline $\begin{array}{l}\text { Gore-Langton et } \\
\text { al. } 2015 \text { [43] }\end{array}$ & $\mathrm{Y}$ & $\mathrm{Y}$ & $\mathrm{N}$ & $\mathrm{N}$ & $\mathrm{Y}$ & $\mathrm{Y}$ & $\mathrm{Y}$ \\
\hline $\begin{array}{l}\text { Siddiqui et al. } \\
2015[44]\end{array}$ & $\mathrm{Y}$ & $\mathrm{Y}$ & $\mathrm{N}$ & $\mathrm{N}$ & $\mathrm{Y}$ & $\mathrm{Y}$ & $\mathrm{Y}$ \\
\hline $\begin{array}{l}\text { Ogolla et al. } \\
2013[45]\end{array}$ & & $\mathrm{Y}$ & $\mathrm{N}$ & $\mathrm{NC}$ & $\mathrm{Y}$ & $\mathrm{Y}$ & $\mathrm{Y}$ \\
\hline
\end{tabular}

Y: yes, N: no, NC: not clear, and NR: not reported. 


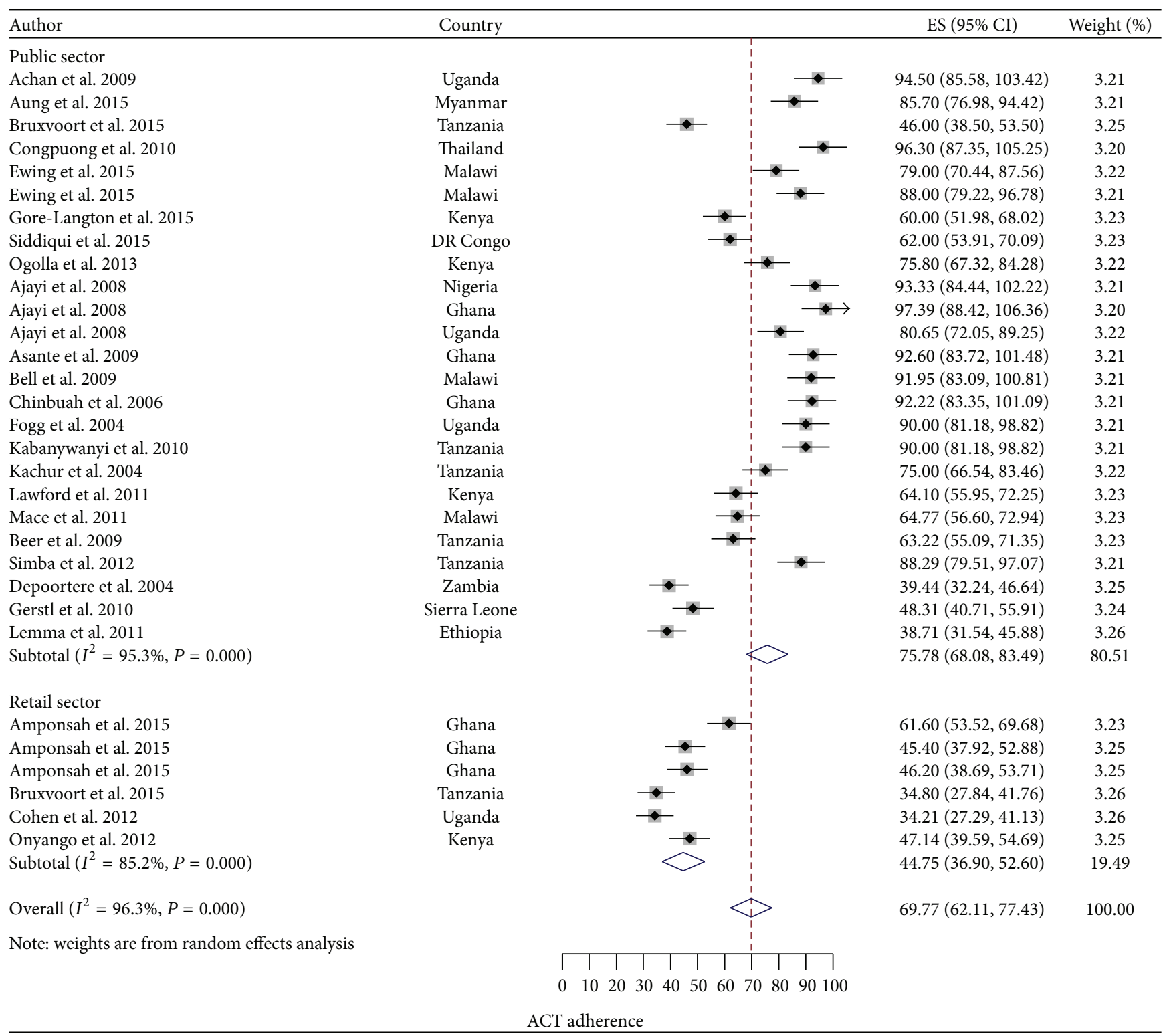

FIGURE 2: Forest plot of prevalence of adherence in the public and retail sectors.

analysis showed that none of the studies exert profound influence on the derived estimates of adherence. From the six studies done in the retail sector the REM pooled prevalence (95\% CI) of adherence to ACT was 44.75\% (36.90\%-77.43\%). Significant statistical heterogeneity was present $\left(I^{2}=96.3 \%\right.$, $P<0.001$ ). No publication bias was detected (Begg's test $P$ value $=0.851$ and Egger's test $P$ value $=0.699)$.

3.2. $A L$ versus $A S-A Q$. When meta-analysis was restricted to the eighteen studies (and two sub-studies) [12, 22, 24, $25,28-31,34-40,42,43,45]$ that administered AL, the REM pooled prevalence of adherence (95\% CI) was $70.52 \%$ $(60.82 \%-80.22 \%)$. No publication was detected (Begg's test $P$ value $=0.056$ and Egger's test $P$ value $=0.018)$. From the six studies $[22,23,26,27,38,44]$ that administered AS-AQ, the
REM pooled prevalence of adherence (95\%CI) was $68.05 \%$ (50.90\%-85.19\%). No publication bias was detected (Begg's and Egger's tests $P$ values were 0.133 and 0.003 , resp.).

3.3. High versus Low to Moderate Malaria Transmission Intensity Areas. From the 13 studies (and 5 substudies) [22, $23,26,28,30,31,34,35,38,39,41,42,44]$ performed in areas with high malaria transmission intensity, the prevalence (95\% CI) of ACT adherence was 77.88\% (69.08\%-86.67\%). There was publication bias (Begg's and Egger's tests $P$ values were 0.002 and 0.001 , resp.). The pooled prevalence $(95 \% \mathrm{CI})$ of ACT adherence from the ten studies (and one substudy) $[12,24,27,29,32,33,36,37,40,45]$ performed in areas with low to moderate malaria transmission intensity was $55.58 \%$ (44.23\%-66.94\%) with nonsignificant $P$ values in both Begg's and Egger's tests (0.640 and 0.237, resp.). 


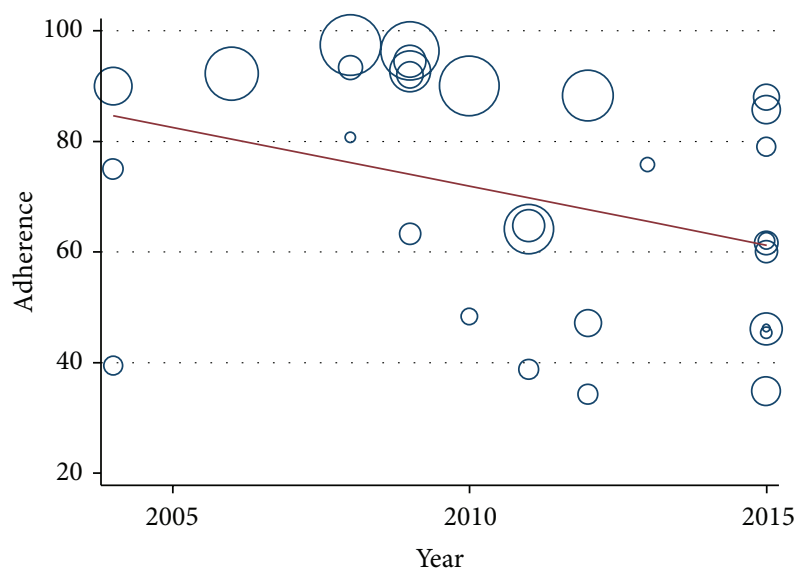

Figure 3: Metaregression of ACT adherence estimate by year of study publication.

3.4. Twice Daily versus Once Daily ACTs. From the eighteen studies (and two substudies) [12, 22-25, 28-31, 34-38, 40, 42, $43,45]$ that used twice daily ACT, the prevalence of adherence was $69.33 \%(59.57 \%-79.09 \%)$. There was publication bias (Begg's test $P$ value $=0.022$ and Egger's test $P$ value $=0.011$ ). From the ten studies $[22,26,27,32,33,38,41,42,44]$ that used once daily ACT, the prevalence of adherence was $66.01 \%$ (52.72\%-79.29\%) with no publication bias (Begg's test $P$ value $=0.074$ and Egger's test $P$ value $=0.001)$.

3.5. Copacked versus Fixed Drug Combination ACTs. The prevalence of adherence to ACT derived from the eleven studies (and one substudy) [22, 23, 26, 27, 32, 33, 38, 40-42, $44]$ that administered copackaged ACT was $66.53 \%$ (54.23\%78.83\%). There was no publication bias (Begg's test $P$ value $=0.075$ and Egger's test $P$ value $=0.008)$. The prevalence of adherence from the nineteen studies (and two substudies) $[12,22,24,25,28-31,34-40,42-45]$ that administered fixed drug combination ACT was $70.11 \%(60.88 \%-79.34 \%)$. There was no publication bias (Begg's test $P$ value $=0.070$ and Egger's test $P$ value $=0.016$ )

3.6. Metaregression. In metaregression analysis the prevalence of adherence to ACT significantly decreases with increasing year of publication as shown in Figure $3(P=$ $0.046,95 \% \mathrm{CI}=-4.223$ to -0.036 ).

3.7. Predictors of ACT Adherence. These are shown in Figures 4 and 5.

\section{Discussion}

This meta-analysis found significantly higher level of adherence to ACT in the public sector as compared to retail sector (76\% and $45 \%$, resp., $P<0.0001$ ). This is not unexpected as the two sectors differ in functions, structure, and quality of services offered. In the public sectors, ACTs are usually given for free and health professionals offer clear instructions on how to take medications. In this meta-analysis some of the included studies done in the public sector provided ACTs

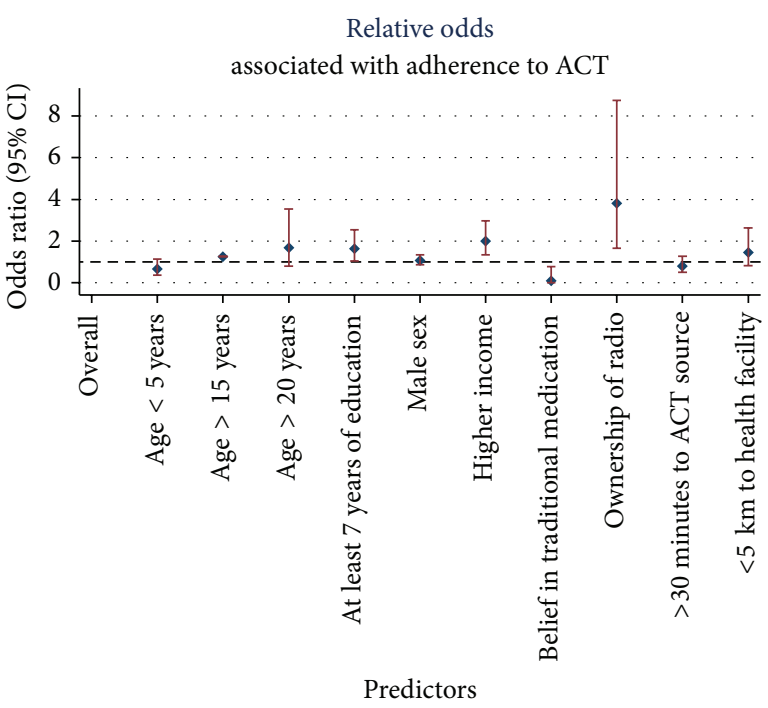

ACT in SSA

FIgURE 4: Sociodemographic predictors of ACT adherence.

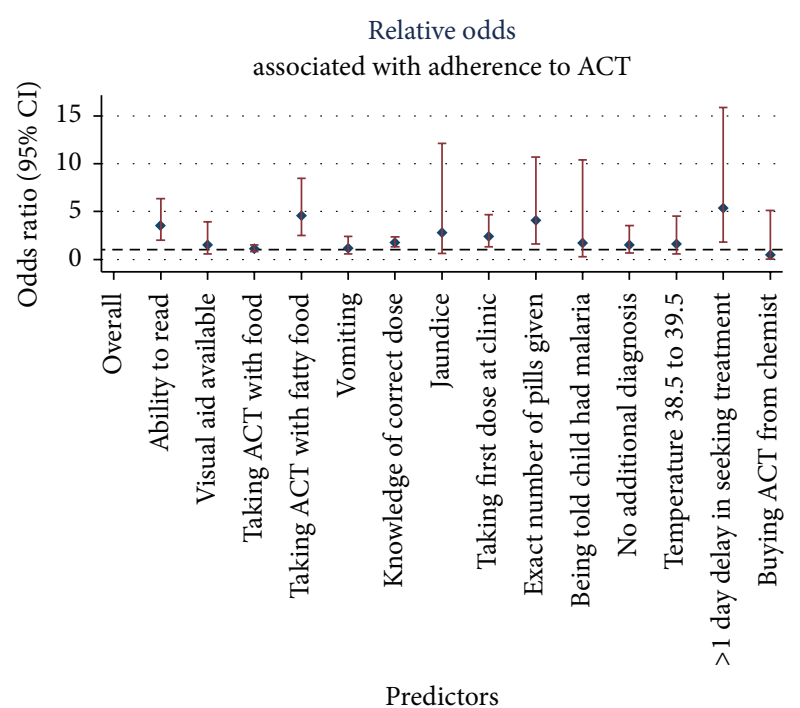

ACT in SSA

FIGURE 5: Clinical and dispensing-related predictors of ACT adherence.

with pictorial instruction. This may enhance compliance and ingestion of correct dosages at the right time. On the other hand the retail sector observations reflect the real life situation in most communities in malaria endemic countries where patients or caregivers of children commonly purchase ACTs from informal private outlets such as drug stores, pharmacies, and supermarkets. These private outlets may or may not be licensed to sell drugs and about $80 \%$ of malaria episodes commonly receive antimalarial therapy in these settings [46]. Diagnoses of malaria in these settings most of the time are presumptive and drugs with questionable potency are dispensed without clear instructions. In drug shops, presumptive treatment of malaria is one of the factors identified to be responsible for the inappropriate 
ACT treatment of most cases [47]. The reported efficacy of ACTs from clinical trials may be difficult to maintain in communities with poor ACT adherence, inappropriate drug policies, substandard drugs, and poor supervision and monitoring by drug regulatory agencies.

This meta-analysis found poor adherence in children less than five years of age which may be related to the lack of appropriate dose formulations for this vulnerable age group [30]. This is a major threat to global efforts to roll back malaria. The probability of developing drug resistant malaria species is higher in children less than five years of age than in adults because of higher parasite biomass in children [36]. In places of low intensity malaria transmission, poorly or incompletely treated malaria infections in the presence of a high parasite biomass could promote development of de novo resistance to antimalarial drugs [48]. Due to the high cost of ACT, parents or caregivers of children may favour traditional medication over ACT. Moreover, coadministration of ACT with traditional medication could lead to treatment interruption, subtherapeutic drug concentration, poor parasitological and clinical response, and nonadherence. Findings from this meta-analysis indicate that lower socioeconomic status (SES) predicts poor adherence to ACT. Children from poorer families may not receive optimum treatment and care during episodes of malaria infection as compared to children from richer families [49]. The role of SES in ACT adherence is multidimensional because some of the factors associated with good adherence to ACT from this meta-analysis may be directly or indirectly related to SES. These factors include ability to read, ownership of radio, and education. Other factors we found to be associated with good adherence to ACT include instructing patients or caregivers to ingest ACT with fatty food, receiving the exact number of pills required for full treatment, and knowledge of correct ACT dose. These dispensing-related factors could positively influence adherence where the pharmacists or healthcare workers routinely practice them while dispensing ACT. Proper communication skills could promote adherence to ACT as we observed in this meta-analysis. Informing caregivers or parents that their child had malaria and availability of visual aid to enhance understanding of dosing instructions were associated with good adherence. Severity of malaria at presentation may determine the level of adherence as we found that patients with jaundice and high body temperature at presentation had good adherence to ACT. Patients, parents, or caregivers of children may perceive these symptoms as serious thereby promoting adherence with treatment instructions.

The cost of ACT is up to 20 times that of previous conventional drugs such as chloroquine and sulphadoxinepyrimethamine used for the treatment of uncomplicated malaria. The high cost of ACT together with the cost of effecting policy change may have contributed to the delay in adopting ACT as the first line choice for uncomplicated malaria in resource poor settings. Concern over the safety of ACTs had also contributed to delay in adopting it as first line therapy. Neurotoxicity manifesting as hearing loss has been reported with use of coartemether to treat uncomplicated malaria [50]. Moreover, safety of ACT in pregnancy has not been established.
We observed fairly similar levels of adherence to AL and AS/AQ (71\% and $80 \%$, resp., $P=0.139$ ) in the current meta-analysis. It has been reported that adherence to antimalarial agents is inversely proportional to length of therapy and frequency of taking dosages [51]. The complete treatment of uncomplicated malaria requires a patient to take 6 doses of AL as compared to 3 doses for other ACTbased combinations [5]. Despite the increased dosages of AL over AS/AQ, we did not observe a statistically significant difference in adherence to these antimalarial agents. Further, fairly similar levels of adherence were observed between single and twice daily ACTs in this meta-analysis (66\% and $69 \%$, resp., $P=0.651$ ). Adherence to copackaged ACTs was also fairly similar to that of fixed drug combination ACTs (67\% and $70 \%$, resp., $P=0.649$ ). However, it is worthy to note that the accuracy of adherence to copackaged ACTs is limited by publication bias. Further studies are needed to assess the influence of dosing regimen complexity, copackaging, and fixed drug combination on adherence to ACT.

It was observed in this study that poor adherence to ACT was mainly in the last two doses at the end of treatment $[25,28,35,45]$. This may be related to the rapid resolution of symptoms after the first few doses which caregivers or patients wrongly interpret as cure. For economic reasons some patients may be tempted to keep remaining tablets for anticipated episodes of malaria.

Substandard antimalarial drugs pose a major threat to global efforts to combat malaria. A survey of drugs conducted in 21 countries in SSA found substantial proportion of drugs that failed chemical and packaging analysis while others were falsified [52]. Poor quality ACTs in addition to poor adherence could amplify the rate at which multidrug resistant malaria strains develop [53]. Resistance to artemisinin has already been reported $[54,55]$ and efforts to curtail this resistance should consider level of poor adherence to ACT in the retail sector, public sector, and areas with low to moderate malaria transmission intensity. It was observed in this meta-analysis that adherence to ACT in areas with high malaria transmission intensity was significantly higher than adherence in areas with low to moderate transmission intensity ( $78 \%$ and $56 \%$, resp., $P=0.001)$. This poor adherence to ACT in areas with low to moderate malaria transmission intensity is a major concern because drug resistant Plasmodium falciparum infection may spread more rapidly in this setting $[56,57]$.

Several caveats should be considered while interpreting the findings from this meta-analysis. Self-report used to assess adherence when blister pack is not available for verification is not a good measure of adherence due to recall bias. Only one study [28] used electronic pill-box monitoring which is a more accurate way of assessing adherence [58]. Different thresholds of adherence were used in the studies and include percentage of correctly ingested doses or number of tablets left on day three. Determination of blood concentration of drugs to confirm adherence was done only in 4 studies [28, 31, 35, 41] and self-report of adherence was found to have a failure rate of $2.4 \%$ in one of the studies [41]. Although assaying blood levels of ACTs could increase accuracy of defining adherence, its role in this meta-analysis 
TABLE 3: ACT recommended in different countries [7].

\begin{tabular}{|c|c|c|}
\hline Continent & ACT recommended & Countries \\
\hline \multirow{3}{*}{ Africa } & $\mathrm{AL}$ & $\begin{array}{l}\text { Angola, Benin, Burkina Faso, CAR, Chad, Comoros, Ethiopia, South Africa, } \\
\text { Tanzania, Togo, Zambia, Zimbabwe, Côte d'Ivoire, Djibouti, Gabon, Malawi, } \\
\text { Mozambique, Sudan (N), Sao Tome and Principe, and Tanzania }\end{array}$ \\
\hline & AS/AQ & $\begin{array}{l}\text { Burundi, Cameroon, Côte d'Ivoire, Democratic Republic of the Congo, } \\
\text { Equatorial Guinea Gabo, Ghana, Liberia, Madagascar, Malawi, Mauritania, } \\
\text { Senegal, Sao Tome and Principe, Sierra Leone, Sudan (S), and Tanzania }\end{array}$ \\
\hline & AS/SP & Mozambique, Djibouti, Somalia, South Africa, and Sudan (N) \\
\hline \multirow{6}{*}{ Asia } & AS/MQ & Cambodia, Malaysia, Myanmar, and Thailand \\
\hline & $\mathrm{AL}$ & Bangladesh, Bhutan, Laos, and Saudi Arabia \\
\hline & AS/AQ & Indonesia \\
\hline & AS/SP & Afghanistan, India, Iran, Tajikistan, Yemen, and Papua New Guinea \\
\hline & $\mathrm{DP}$ & Vietnam \\
\hline & $\mathrm{AL}$ & Iran, Philippines, and Solomon Islands \\
\hline \multirow{3}{*}{ South America } & AS/SP & Ecuador, Peru \\
\hline & AS/MQ & Bolivia, Peru, and Venezuela \\
\hline & $\mathrm{AL}$ & Brazil, Guyana, and Suriname \\
\hline
\end{tabular}

AL: artemether-lumefantrine, AQ: amodiaquine, AS: artesunate, DA/PQ: dihydroartemisinin/piperaquine, MQ: mefloquine, and SP: sulphadoxinepyrimethamine.

may be limited by pharmacokinetic differences between children and adults. Variable blood concentrations of ACTs could arise from age- or weight-based dosing and ingestion of lumefantrine with fatty meal (instruction not given in some of the studies). Despite these caveats, restricted analysis reduces heterogeneity and confounding thereby increasing reliability of estimates. The strength of this meta-analysis lies in its large sample size (8654 subjects), exclusion of confounders, and unannounced home visit in most of the studies included (see Table 2). Two recently conducted systematic reviews found wide variability of ACT adherence across different populations $[10,11]$. In these reviews there are no pooled estimates of prevalence of adherence and this could undermine their epidemiologic significance. The current study also encountered variability of reported ACT adherence arising from environmental factors. However, effort was made to substantially reduce heterogeneity between studies by metaanalytically pooling estimates from fairly similar populations via restricted analysis.

Currently ACT is the best and recommended first line therapy for uncomplicated malaria in several countries (see Table 3) [7]. To maintain its long term efficacy there is a need to train healthcare providers on appropriate dosing and dispensing of ACT. The poor adherence observed in the retail sector and areas with low to moderate malaria transmission and suboptimal adherence in public sector calls for more efforts to improve adherence to ACT in malaria endemic countries of the world. Barriers to adherence should be addressed because nonadherence could be a platform for the development of antimalarial resistance. At community level people should be educated on the adverse effects and implications of poor adherence to ACT. Training of healthcare providers and adequate supply of subsidized potent ACTs with clear instructions and packaging leaflets in local languages could improve adherence. Furthermore, pictorial instructions could help bridge the communication gap that may exist between health professionals and patients or caregivers.

\section{Conclusion}

Findings from this systematic review and meta-analysis indicated that adherence to ACT in the retail sector and areas with low/moderate malaria transmission are poor. Healthcare providers, policy makers, and other stakeholders involved in malaria control programs should take cognisance of these findings when designing targeted interventions to improve ACT adherence. Educational programs to increase awareness and understanding of ACT dosing regimen are interventions urgently needed to improve adherence to ACT. Patients or caregivers should be provided with an adequate explanation at the time of prescribing and/or dispensing ACT. Prescribers, dispensers, and vendors should, therefore, give a clear and comprehensible explanation on how to use ACT. User-friendly packaging (e.g., blister packs) should be used to encourage completion of the treatment course and correct dosing.

\section{Conflict of Interests}

The authors declare that they have no conflict of interests.

\section{Authors' Contribution}

Ahmad M. Yakasai and Muhammad Hamza conceived and designed the study. Ahmad M. Yakasai and Muhammad Hamza ran the searches and extracted the data and Fatimah Hassan-Hanga resolved the discrepancies. Ahmad M. Yakasai, Fatimah Hassan-Hanga, Muhammad Hamza, 
and Mahmood M. Dalhat analyzed the data. All the authors interpreted the data, wrote the paper, and approved the final version.

\section{References}

[1] T. K. Mutabingwa, "Artemisinin-based combination therapies (ACTs): best hope for malaria treatment but inaccessible to the needy!" Acta Tropica, vol. 95, no. 3, pp. 305-315, 2005.

[2] Tanzanian National Bureau of Statistics, Household Budget Survey, 2001, http://www.nbs.go.tz/tnada/index.php/ddibrowser/1.

[3] World Health Organization, "Antimalarial drug combination therapy. Report of a WHO technical consultation," WHO/CDS/ RBM 2001.35, World Health Organization, Geneva, Switzerland, 2001.

[4] International Artemisinin Study Group, "Artesunate combinations for treatment of malaria: meta-analysis," The Lancet, vol. 363, no. 9402, pp. 9-17, 2004.

[5] S. Y. Whegang, R. Tahar, V. N. Foumane et al., "Efficacy of non-artemisinin- and artemisinin-based combination therapies for uncomplicated falciparum malaria in Cameroon," Malaria Journal, vol. 9, no. 1, article 56, 2010.

[6] World Health Organization, Antimalarial Drug Combination Therapy: Report of a Technical Consultation, WHO, Geneva, Switzerland, 2001.

[7] A. Bosman and K. N. Mendis, "A major transition in malaria treatment: the adoption and deployment of artemisinin-based combination therapies," American Journal of Tropical Medicine and Hygiene, vol. 77, supplement 6, pp. 193-197, 2007.

[8] G. O. Adjei, A. K. Darkwah, B. Q. Goka et al., "Parents' perceptions, attitudes and acceptability of treatment of childhood malaria with artemisinin combination therapies in Ghana," Ghana Medical Journal, vol. 42, no. 3, pp. 99-106, 2008.

[9] K. Yeboah-Antwi, J. O. Gyapong, I. K. Asare, G. Barnish, D. B. Evans, and S. Adjei, "Impact of prepackaging antimalarial drugs on cost to patients and compliance with treatment," Bulletin of the World Health Organization, vol. 79, no. 5, pp. 394-399, 2001.

[10] K. Banek, M. Lalani, S. G. Staedke, and D. Chandramohan, "Adherence to artemisinin-based combination therapy for the treatment of malaria: a systematic review of the evidence," Malaria Journal, vol. 13, no. 1, article 7, 2014.

[11] K. Bruxvoort, C. Goodman, S. P. Kachur, and D. Schellenberg, "How patients take malaria treatment: a systematic review of the literature on adherence to antimalarial drugs," PLOS ONE, vol. 9, no. 1, Article ID e84555, 15 pages, 2014.

[12] E. O. Onyango, G. Ayodo, C. A. Watsierah et al., "Factors associated with non-adherence to Artemisinin-based combination therapy (ACT) to malaria in a rural population from holoendemic region of western Kenya," BMC Infectious Diseases, vol. 12, article 143, 2012.

[13] S. H. Downs and N. Black, "The feasibility of creating a checklist for the assessment of the methodological quality both of randomised and non-randomised studies of health care interventions," Journal of Epidemiology and Community Health, vol. 52, no. 6, pp. 377-384, 1998.

[14] D. Moher, A. Liberati, J. Tetzlaff, and D. G. Altman, "Preferred reporting items for systematic reviews and meta-analyses: the PRISMA statement," PLoS Medicine, vol. 6, no. 7, Article ID e1000097, 2009.

[15] D. F. Stroup, J. A. Berlin, S. C. Morton et al., "Meta-analysis of observational studies in epidemiology: a proposal for reporting. Meta-analysis Of Observational Studies in Epidemiology
(MOOSE) group," The Journal of the American Medical Association, vol. 283, no. 15, pp. 2008-2012, 2000.

[16] R. DerSimonian and N. Laird, "Meta-analysis in clinical trials," Controlled Clinical Trials, vol. 7, no. 3, pp. 177-188, 1986.

[17] C. B. Begg and M. Mazumdar, "Operating characteristics of a rank correlation test for publication bias," Biometrics, vol. 50, no. 4, pp. 1088-1101, 1994.

[18] M. Egger, G. D. Smith, M. Schneider, and C. Minder, "Bias in meta-analysis detected by a simple, graphical test," British Medical Journal, vol. 315, no. 7109, pp. 629-634, 1997.

[19] J. P. T. Higgins, S. G. Thompson, J. J. Deeks, and D. G. Altman, "Measuring inconsistency in meta-analyses," The British Medical Journal, vol. 327, no. 7414, pp. 557-560, 2003.

[20] J. Lau, J. P. A. Ioannidis, N. Terrin, C. H. Schmid, and I. Olkin, "The case of the misleading funnel plot," British Medical Journal, vol. 333, no. 7568, pp. 597-600, 2006.

[21] A. Tobias, "Assessing the influence of a single study in the metaanyalysis estimate," Stata Technical Bulletin, vol. 8, no. 47, pp. 15-17, 1999.

[22] I. O. Ajayi, E. N. Browne, B. Garshong et al., "Feasibility and acceptability of artemisinin-based combination therapy for the home management of malaria in four African sites," Malaria Journal, vol. 7, article 6, 2008.

[23] K. P. Asante, R. Owusu, D. Dosoo et al., "Adherence to artesunate-amodiaquine therapy for uncomplicated malaria in rural ghana: a randomised trial of supervised versus unsupervised drug administration," Journal of Tropical Medicine, vol. 2009, Article ID 529583, 7 pages, 2009.

[24] H. Lawford, D. Zurovac, L. O’Reilly et al., "Adherence to prescribed artemisinin-based combination therapy in Garissa and Bunyala districts, Kenya," Malaria Journal, vol. 10, article 281, 2011.

[25] A. M. Kabanywanyi, C. Lengeler, P. Kasim et al., "Adherence to and acceptability of artemether-lumefantrine as first-line anti-malarial treatment: evidence from a rural community in Tanzania," Malaria Journal, vol. 9, no. 1, article 48, 2010.

[26] S. Gerstl, S. Dunkley, A. Mukhtar, S. Baker, and J. Maikere, "Successful introduction of artesunate combination therapy is not enough to fight malaria: results from an adherence study in Sierra Leone," Transactions of the Royal Society of Tropical Medicine \& Hygiene, vol. 104, no. 5, pp. 328-335, 2010.

[27] N. Beer, A. S. Ali, G. Rotllant et al., "Adherence to artesunateamodiaquine combination therapy for uncomplicated malaria in children in Zanzibar, Tanzania," Tropical Medicine and International Health, vol. 14, no. 7, pp. 766-774, 2009.

[28] D. J. Bell, D. Wootton, M. Mukaka et al., "Measurement of adherence, drug concentrations and the effectiveness of artemether-lumefantrine, chlorproguanil-dapsone or sulphadoxine-pyrimethamine in the treatment of uncomplicated malaria in Malawi," Malaria Journal, vol. 8, no. 1, article 204, 2009.

[29] H. Lemma, C. Löfgren, and M. S. Sebastian, "Adherence to a six-dose regimen of artemether-lumefantrine among uncomplicated Plasmodium falciparum patients in the Tigray Region, Ethiopia," Malaria Journal, vol. 10, article 349, 2011.

[30] K. E. Mace, D. Mwandama, J. Jafali et al., "Adherence to treatment with artemether-lumefantrine for uncomplicated malaria in Rural Malawi," Clinical Infectious Diseases, vol. 53, no. 8, pp. 772-779, 2011.

[31] C. Fogg, F. Bajunirwe, P. Piola et al., "Adherence to a sixdose regimen of artemether-lumefantrine for treatment of uncomplicated Plasmodium falciparum malaria in Uganda," 
American Journal of Tropical Medicine and Hygiene, vol. 71, no. 5, pp. 525-530, 2004.

[32] S. P. Kachur, R. A. Khatib, E. Kaizer, S. S. Fox, S. M. Abdulla, and P. B. Bloland, "Adherence to antimalarial combination therapy with sulfadoxine-pyrimethamine and artesunate in rural Tanzania," American Journal of Tropical Medicine and Hygiene, vol. 71, no. 6, pp. 715-722, 2004.

[33] E. Depoortere, J.-P. Guthmann, N. Sipilanyambe et al., "Adherence to the combination of sulphadoxine-pyrimethamine and artesunate in the Maheba refugee settlement, Zambia," Tropical Medicine and International Health, vol. 9, no. 1, pp. 62-67, 2004.

[34] A. M. Chinbuah, J. O. Gyapong, F. Pagnoni, E. K. Wellington, and M. Gyapong, "Feasibility and acceptability of the use of artemether-lumefantrine in the home management of uncomplicated malaria in children 6-59 months old in Ghana," Tropical Medicine and International Health, vol. 11, no. 7, pp. 1003-1016, 2006.

[35] D. O. Simba, D. Kakoko, G. Tomson et al., "Adherence to artemether/lumefantrine treatment in children under real-life situations in rural Tanzania," Transactions of the Royal Society of Tropical Medicine and Hygiene, vol. 106, no. 1, pp. 3-9, 2012.

[36] J. L. Cohen, E. Yavuz, A. Morris, J. Arkedis, and O. Sabot, "Do patients adhere to over-the-counter artemisinin combination therapy for malaria? Evidence from an intervention study in Uganda," Malaria Journal, vol. 11, article 83, 2012.

[37] J. Achan, J. K. Tibenderana, D. Kyabayinze et al., "Effectiveness of quinine versus artemether-lumefantrine for treating uncomplicated falciparum malaria in Ugandan children: randomised trial," British Medical Journal, vol. 339, Article ID b2763, pp. 1-8, 2009.

[38] A. O. Amponsah, H. Vosper, and A. F. A. Marfo, "Patient related factors affecting adherence to antimalarial medication in an urban estate in Ghana," Malaria Research and Treatment, vol. 2015, Article ID 452539, 8 pages, 2015.

[39] W. Aung, A. M. Dondorp, M. Min et al., "Assessment of adherence to three day course of artemeter-lumefantrine treatment in Rhakine state, Myanmar," JITMM Proceedings 3, vol. 4, pp. 16-23, 2015.

[40] K. Bruxvoort, A. Kalolella, M. Cairns et al., "Are Tanzanian patients attending public facilities or private retailers more likely to adhere to artemisinin-based combination therapy?" Malaria Journal, vol. 14, no. 1, pp. 1-12, 2015.

[41] K. Congpuong, P. Bualombai, V. Banmairuroi, and K. NaBangchang, "Compliance with a three-day course of artesunatemefloquine combination and baseline anti-malarial treatment in an area of Thailand with highly multidrug resistant falciparum malaria," Malaria Journal, vol. 9, article 43, pp. 2-8, 2010.

[42] V. L. Ewing, D. J. Terlouw, A. Kapinda et al., "Perceptions and utilization of the anti-malarials artemether-lumefantrine and dihydroartemisinin-piperaquine in young children in the Chikhwawa district of Malawi: a mixed methods study," Malaria Journal, vol. 14, article 13, pp. 2-10, 2015.

[43] G. R. Gore-Langton, N. Alenwi, J. Mungai et al., "Patient adherence to prescribed artemisinin-based combination therapy in Garissa County, Kenya, after three years of health care in a conflict setting," Malaria Journal, vol. 14, no. 1, article 125, 10 pages, 2015.

[44] M. R. Siddiqui, A. Willis, K. Bil, J. Singh, E. Mukomena Sompwe, and C. Ariti, "Adherence to artemisinin-based combination therapy for the treatment of uncomplicated malaria in Democratic Republic of the Congo," F1000Research, vol. 4, no. 51, pp. 1-16, 2015.
[45] J. O. Ogolla, S. O. Ayaya, and C. A. Otieno, "Levels of adherence to coartem in the routine treatment of uncomplicated malaria in children aged below five years, in Kenya," Iranian Journal of Public Health, vol. 42, no. 2, pp. 129-133, 2013.

[46] J. Nankabirwa, D. Zurovac, J. N. Njogu et al., "Malaria misdiagnosis in Uganda-implications for policy change," Malaria Journal, vol. 8, no. 1, article 66, 2009.

[47] A. K. Mbonye, S. Lal, B. Cundill, K. S. Hansen, S. Clarke, and P. Magnussen, "Treatment of fevers prior to introducing rapid diagnostic tests for malaria in registered drug shops in Uganda," Malaria Journal, vol. 12, no. 1, article 131, 2013.

[48] N. J. White and W. Pongtavornpinyo, "The de novo selection of drug-resistant malaria parasites," Proceedings of the Royal Society B: Biological Sciences, vol. 270, no. 1514, pp. 545-554, 2003.

[49] J. Armstrong-Schellenberg, C. G. Victora, A. Mushi et al., "Inequities among the very poor: health care for children in rural southern Tanzania," The Lancet, vol. 361, no. 9357, pp. 561566, 2003.

[50] S. Toovey and A. Jamieson, "Audiometric changes associated with the treatment of uncomplicated falciparum malaria with co-artemether," Transactions of the Royal Society of Tropical Medicine and Hygiene, vol. 98, no. 5, pp. 261-267, 2004.

[51] S. Yeung, W. Pongtavornpinyo, I. M. Hastings, A. J. Mills, and N. J. White, "Antimalarial drug resistance, artemisininbased combination therapy, and the contribution of modeling to elucidating policy choices," American Journal of Tropical Medicine and Hygiene, vol. 71, supplement 2, pp. 179-186, 2004.

[52] G. M. L. Nayyar, J. G. Breman, P. N. Newton, and J. Herrington, "Poor-quality antimalarial drugs in Southeast Asia and subSaharan Africa," The Lancet Infectious Diseases, vol. 12, no. 6, pp. 488-496, 2012.

[53] M. Makanga, Z. Premji, C. Falade et al., "Efficacy and safety of the six-dose regimen of artemether-lumefantrine in pediatrics with uncomplicated Plasmodium falciparum malaria: a pooled analysis of individual patient data," American Journal of Tropical Medicine and Hygiene, vol. 74, no. 6, pp. 991-998, 2006.

[54] A. M. Dondorp, S. Yeung, L. White et al., "Artemisinin resistance: current status and scenarios for containment," Nature Reviews Microbiology, vol. 8, no. 4, pp. 272-280, 2010.

[55] A. M. Dondorp, F. Nosten, P. Yi et al., "Artemisinin resistance in Plasmodium falciparum malaria," The New England Journal of Medicine, vol. 361, no. 5, pp. 455-467, 2009.

[56] I. M. Hastings and W. M. Watkins, "Intensity of malaria transmission and the evolution of drug resistance," Acta Tropica, vol. 94, no. 3, pp. 218-229, 2005.

[57] A. O. Talisuna, P. Langi, N. Bakyaita et al., "Intensity of malaria transmission, antimalarial-drug use and resistance in Uganda: what is the relationship between these three factors?" Transactions of the Royal Society of Tropical Medicine and Hygiene, vol. 96, no. 3, pp. 310-317, 2002.

[58] M. Twagirumukiza, P. C. Kayumba, J. G. Kips et al., "Evaluation of medication adherence methods in the treatment of malaria in Rwandan infants," Malaria Journal, vol. 9, no. 1, article 206, 2010. 


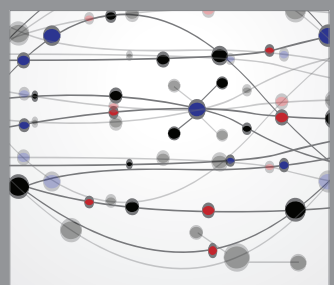

The Scientific World Journal
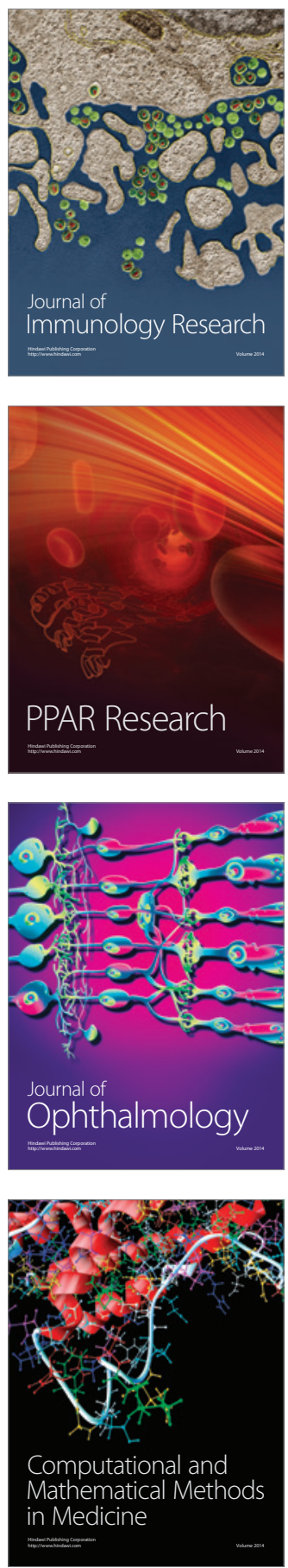

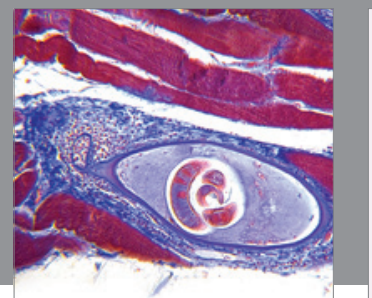

Gastroenterology

Research and Practice
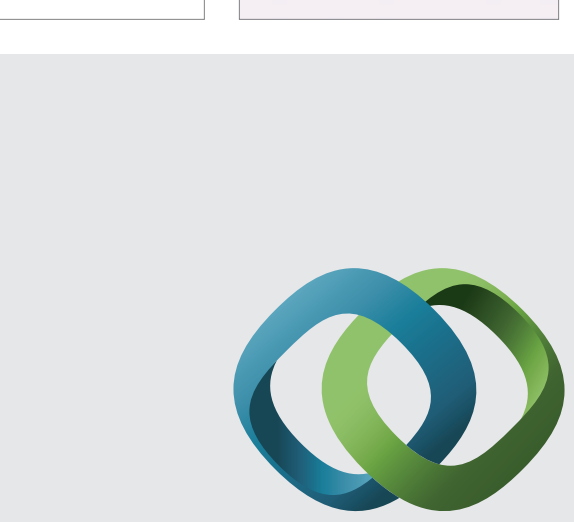

\section{Hindawi}

Submit your manuscripts at

http://www.hindawi.com
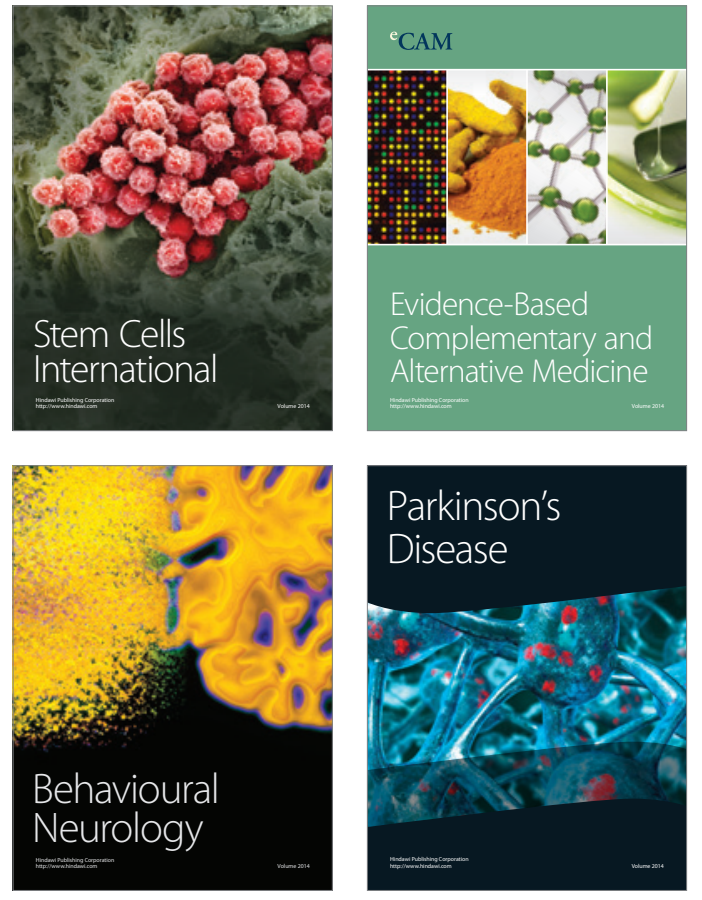
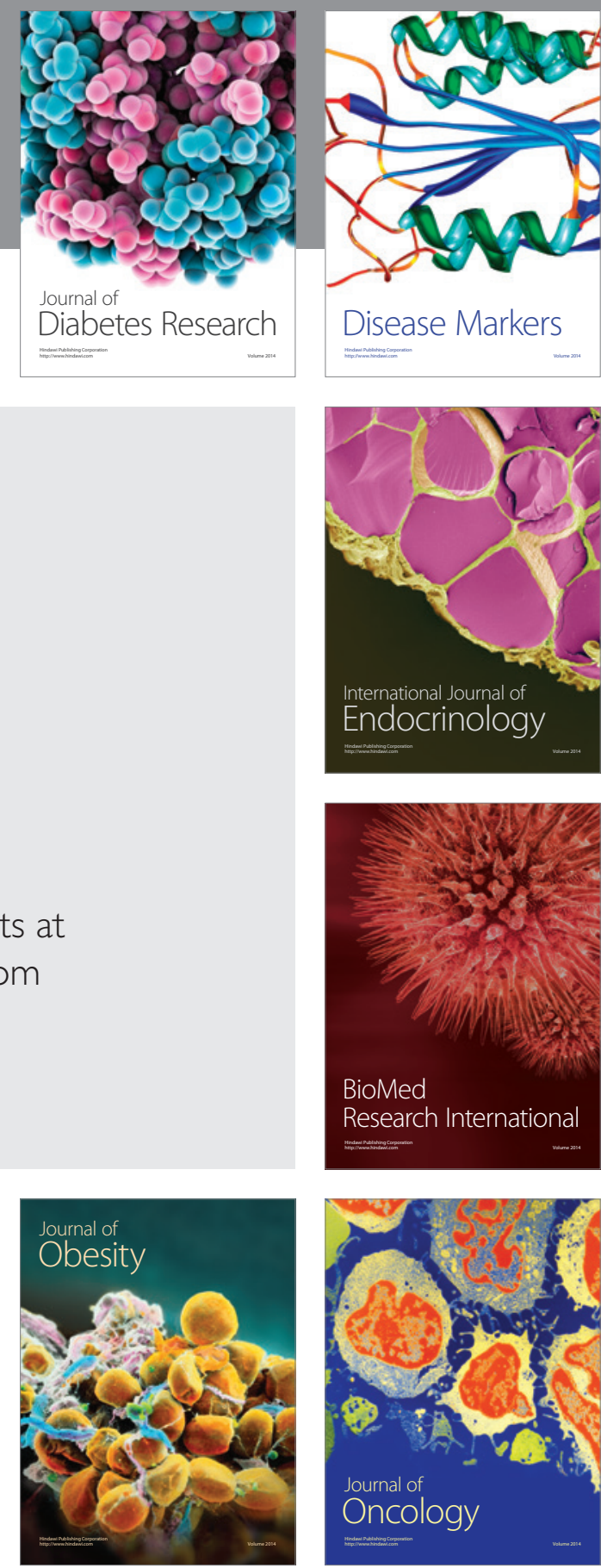

Disease Markers
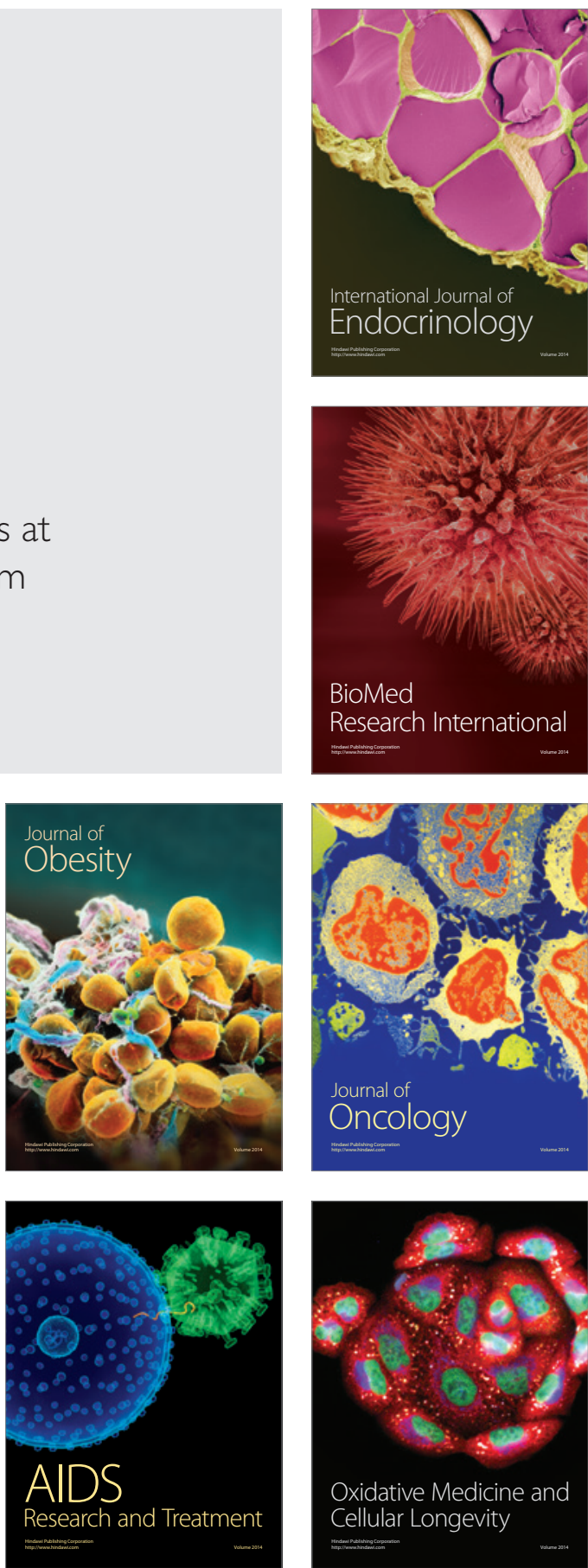